\title{
A case of confusing probability and confirmation
}

\author{
Jeanne Peijnenburg
}

Received: 1 July 2009 / Accepted: 9 November 2009 / Published online: 24 November 2009

C The Author(s) 2009. This article is published with open access at Springerlink.com

\begin{abstract}
Tom Stoneham put forward an argument purporting to show that coherentists are, under certain conditions, committed to the conjunction fallacy. Stoneham considers this argument a reductio ad absurdum of any coherence theory of justification. I argue that Stoneham neglects the distinction between degrees of confirmation and degrees of probability. Once the distinction is in place, it becomes clear that no conjunction fallacy has been committed.
\end{abstract}

Keywords Coherentism · Probability · Confirmation · Conjunction fallacy

\section{Introduction}

Tom Stoneham has presented an argument that, if correct, produces a reductio ad absurdum of any coherence theory of justification (Stoneham 2007). Although Stoneham doubts that the argument can be correct, he confesses that he is unable to find any error. In this contribution I surmise that the difficulty may well spring from a confusion between degrees of confirmation and degrees of probability. Experimental results in cognitive psychology have recently shown that many people actually rely on assessments of confirmation when they are judging probabilities, and that this might explain the apparent occurrence of a conjunction fallacy (Crupi et al. 2008). It seems to me that Stoneham might have done the same thing: because he fails to distinguish between probability judgements and confirmation assessments, he mistakenly thinks that a coherentist true to his colours must, under certain conditions, commit the conjunction fallacy. In Sect. 1, I give a précis of Stoneham's argument, attempting

\footnotetext{
J. Peijnenburg $(\varangle)$

Faculty of Philosophy, University of Groningen, Oude Boteringestraat 52,

9712 GL Groningen, The Netherlands

e-mail: jeanne.peijnenburg@rug.nl
} 
to stay as close as possible to Stoneham's reasoning and notation. Then, in Sect.2, I explain how he may have gone astray.

\section{A précis of Stoneham's argument}

Stoneham (2007, p. $\left.254^{1}\right)$ begins his argument with a description of coherentism:

(1) There are finite sets of beliefs such that each member of the set is epistemically supported by some other member, and nothing else.

Then he develops a reductio of (1), culminating on the last page of his paper in its negation:

(not-1) For any finite set of beliefs all of which have some positive degree of epistemic support, at least one member of that set does not receive its support entirely from the other members of the set.

Stoneham (p. 257) calls (not-1) "a pretty good definition of foundationalism", thereby implying that his reductio of coherentism may well serve as a proof of the foundationalist's stance.

The crucial term in (1) is 'epistemic support', which Stoneham (p. 254) defines as: "A belief $\mathrm{b}(p)$ is epistemically supported by the belief $\mathrm{b}(q)$ iff $\mathrm{b}(p)$ 's justifiedness ... consists in part in $\mathrm{b}(p)$ standing in some relation of dependence to $\mathrm{b}(q)$." - italics by the author. The exact contents of the dependence relation is according to Stoneham (ibid.) "a matter of debate between coherentists".

Stoneham's next step is to formulate a necessary condition of epistemic support:

(2) The relation of epistemic support is quasi-transitive.

Following a suggestion by Shackel (2008, p. 226), I have added the prefix 'quasi' to make clear that Stoneham wants to exclude any belief that epistemically supports itself. In other words, if a belief in $p$ supports a belief in $q$, and a belief in $q$ supports a belief in $r$, then a belief in $p$ supports a belief in $r$ only on condition that $p \neq r$. From (1) and (2) Stoneham derives:

(3) The relation of epistemic support is not asymmetric.

Here is the derivation fully spelled out (p. 255):

From (1), $b_{1}$ is supported by $b_{2}$ and $b_{1} \neq b_{2}, b_{2}$ is supported by $b_{3}$ and $b_{2} \neq$ $b_{3}, b_{3}$ is supported by $b_{4}$ etc. Since the set is finite, for some $i$ and $j, b_{i}=b_{j}$. Without loss of generality suppose there are only three beliefs and $b_{1}=b_{4}$. Then $b_{3}$ is supported by $b_{1}$. Since $b_{1}$ is supported by $b_{2}$ and $b_{2}$ is supported by $b_{3}$, by transitivity - ... provided $b_{1} \neq b_{3}-b_{1}$ is supported by $b_{3}$. So the relation is not asymmetric.

Stoneham (ibid.) then derives (4) from (3):

\footnotetext{
$\overline{1}$ All the references to Stoneham are to Stoneham (2007).
} 
(4) For some $p$ and $q$ and some thinker at some time, it is possible that the belief that $p \& q$ is better supported [by a certain stock $S$ of beliefs-JP] than the belief that $p$ or the belief that $q$ alone.

Stoneham's reasoning (ibid.) behind this derivation is as follows:

From (3) it is possible that there is a subject with stock of beliefs $S$ such that $\mathrm{b}(p)$ supports $\mathrm{b}(q)$ in the presence of $S \ldots$ and $\mathrm{b}(q)$ supports $\mathrm{b}(p)$ in the presence of $S \ldots$. Since, in the presence of $S, \mathrm{~b}(p)$ supports $\mathrm{b}(q)$ and vice versa, $\mathrm{S}+\mathrm{b}(p)$ provides more support for $\mathrm{b}(q)$ than $S$ alone and $S+\mathrm{b}(q)$ provides more support for $\mathrm{b}(p)$ than $S$ alone. Suppose a subject has $S$ but not $\mathrm{b}(p)$ or $\mathrm{b}(q)$ and that $S$ does not support $\mathrm{b}(p)$ or $\mathrm{b}(q)$ or $\mathrm{b}(\neg p)$ or $\mathrm{b}(\neg q)$. Then if the subject adds just $\mathrm{b}(p)$ or just $\mathrm{b}(q)$, he will be adding a belief with [less] support, but if he adds both he will be adding a belief (viz. $\mathrm{b}(p \& q)$ ) with [more] support. ${ }^{2}$

Stoneham's point may be illustrated by the epistemological situation of Mr. Cohen, who has been a lifelong coherentist. Mr. Cohen has a stock of background beliefs, $S$, and he is now entertaining two propositions, $p$ and $q$, neither of which is contained in $S$. After careful scrutiny, Cohen concludes that $S$ does not really support either $p$ or $q$ : the support imparted by $S$ does not pass a particular threshold necessary for adding $p$ or $q$ to $S$. For Stoneham this means that $S$ is neutral with respect to both $p$ and $q$; the epistemic support that $S$ gives to $p$ is the same as the epistemic support that $S$ gives to $\sim p$, and similarly for $q$ and $\sim q .^{3}$

However, Cohen notices that there is great mutual coherence between $p$ and $q$. Indeed, $p$ and $q$ can even be said to support one another in the following sense. If our coherentist were to add $p$ to $S$, the composite system $p \& S$ would support $q$ more that $S$ alone, and in fact would pass the threshold. Similarly, if he were to add $q$ to $S$, the complex $q \& S$ would support $p$ more than $S$ alone, and the support would pass the threshold. As Stoneham sees it, this fact makes it more reasonable for a coherentist to add the conjunction $p \& q$ to his $S$ than to add only $p$ or only $q$. For although $p$ or $q$ might not be very believable when taken separately, they display a great mutual coherence (in the presence of $S$ ), for they both point in the same direction and jointly acquire a plausibility that neither of them has alone.

Note that, until now, there has not been any mentioning of probability. And this is no accident. As Stoneham has explained to me in private communication, he has difficulties with any criticism that brings in probability at the beginning, because his intention was to complete the argument on epistemic support before saying anything about probability. The word 'probability' makes its first appearance when Stoneham introduces his Axiom 5:

\footnotetext{
2 Stoneham's text has: "Then if the subject adds just $\mathrm{b}(p)$ or just $\mathrm{b}(q)$, he will be adding a belief with no support, but if he adds both he will be adding a belief (viz. $\mathrm{b}(p \& q)$ ) with positive support." However, later Stoneham states that the terms 'no support' and 'positive support' are only used to simplify the expression: "the only assumption we really needed was that $S+\mathrm{b}(p)$ provides more support for $\mathrm{b}(q)$ than $S$ alone and $S+\mathrm{b}(q)$ provides more support for $\mathrm{b}(p)$ than $S$ alone. And that must be the case for any $S$ in the presence of which $\mathrm{b}(p)$ supports $\mathrm{b}(q)$ and vice versa."

${ }^{3}$ Stoneham sets the degree of support in all these cases at 0.5 , as he explained to me in private email communication. So if the epistemic support, E, that $S$ gives to $q$ is neutral, then Stoneham writes $\mathrm{E}(q, S)=0.5$. And if the epistemic support that $S$ and $p$ give to $q$ is positive, he writes: $\mathrm{E}(q, S \& p)>0.5$.
} 
(5) The belief that $p$ epistemically supports the belief that $q$ only if $p$ raises the probability of $q$.

From (4) and (5) it follows that the probability of $p \& q$ is greater than that of $p$ or $q$ :

(6) $\operatorname{pr}(p \& q)>\operatorname{pr}(p)$ or $\operatorname{pr}(p \& q)>\operatorname{pr}(q)$,

which is the conjunction fallacy. Stoneham (p. 255) reasons:

These probabilities are credences. Suppose our subject has belief set $S$ and comes to consider $p$ and $q$, then the credence of $p$ is 0.5 but the credence of $p \& q$ is $>0.5$.

The final conclusion then is that Mr. Cohen and his fellow-coherentists are committed to a notion of epistemic support that violates the probability calculus. Stoneham regards this as a reductio of coherentism.

\section{Where is the flaw?}

Although Stoneham believes that his argument is incorrect, he states that he is unable to find the flaw. He argues that the flaw cannot lie in (1), for (1) is "characteristic for [the coherentist's] view" (p. 256). The transitivity condition (2) is "pretty much analytic" (ibid.), and premise (3) was correctly derived from (1) and (2). Premise (4) cannot be the culprit either, since it has been correctly inferred from (3). That leaves us with (5), about which Stoneham (p. 256) writes:

(5) might be a matter of debate, but it is hard to see how there could be counterexamples .... How can $p$ give us any reason to believe $q$ is true if the truth of $p$ does not make $q$ any more likely?

However, I think that (5) is a clear illustration of the flaw in Stoneham's argument. In order to see that, we must first realise that Stoneham's notion of epistemic support has all the characteristics of a measure of confirmation. The two constraints that Stoneham imposes on epistemic support, namely that it is quasi-transitive and not asymmetric, are also properties of confirmation. There exist many different measures of confirmation (for overviews see Fitelson 1999; Crupi et al. 2007). All of these measures are not asymmetric, and Shogenji (2003) has shown that they are also consistent with transitivity. ${ }^{4}$ But no matter how natural and intuitive it is to interpret Stoneham's ' $p$ epistemically supports $q$ ' as ' $p$ confirms $q$ ', none of the people that reacted to Stoneham seem to have noticed it. This goes equally for Stoneham's critics (Noordhof 2007; Jäger 2007; Rowbottom 2007) as for his defender (Shackel 2008); indeed, I myself at first overlooked it.

The most simple and popular degree of confirmation is Carnap's measure D, which is the conditional probability of $p$, given $S$, minus the unconditional probability of $p$ :

$$
\mathrm{D}(p, S)=\operatorname{pr}(p \mid S)-\operatorname{pr}(p),
$$

\footnotetext{
4 All the common measures of confirmation share the property that, if $p$ confirms $q$, then $q$ confirms $p$, although not in general to the same degree. So all confirmation measures are not asymmetric. Transitivity of confirmation, as of probabilistic support, is not in general true, but under the "nearest neighbour screening-off' restriction it is so (Shogenji 2003). So confirmation measures can be transitive.
} 
In the rest of this paper I shall define Stoneham's notion of epistemic support in terms of D. However, no strings are attached to that: everything I say would apply if I were to define 'confirmation' with any other of the existing Bayesian confirmation measures.

Once we have defined 'confirmation' in this way, we can see that axiom (5) is ambiguous: it has two interpretations. The first interpretation is given in (5a):

$$
\text { If } \mathrm{D}(q, p \& S)>\mathrm{D}(q, S) \text { then } \operatorname{pr}(q \mid p \& S)>\operatorname{pr}(q \mid S)^{5}
$$

The other one is $(5 b)$ :

$$
\text { If } \mathrm{D}(p \& q, S)>\mathrm{D}(q, S) \text { then } \operatorname{pr}(p \& q \mid S)>\operatorname{pr}(q \mid S) \text {. }
$$

Interpretation (5a) sits badly with at least two important passages in Stoneham's text. First, it does not sit well with Stoneham's claim that, for a coherentist, adding a conjunction to his stock of beliefs can be more rational than adding only one of the conjuncts. Stoneham's reason for this claim is, as we have seen, that a conjunction can be better supported than one of the conjuncts. However, in (5a) there is no question of a conjunction being supported. The conjunction appearing in (5a) gives support, it does not receive it. Second, (5a) is at odds with the fact that Stoneham's calls (5) an axiom. For (5a) is not an axiom, it is a definition of epistemic support. As such it goes both ways: not only is it the case that, if $\mathrm{D}(q, p \& S)>\mathrm{D}(q, S)$ then $\operatorname{pr}(q \mid p \& S)>\operatorname{pr}(q \mid S)$, but it is also the case that, if $\operatorname{pr}(q \mid p \& S)>\operatorname{pr}(q \mid S)$, then $\mathrm{D}(q, p \& S)>\mathrm{D}(q, S)$.

So Stoneham must have meant interpretation (5b). But while (5a) is a logical truth, (5b) is a logical falsehood; its consequent is always false. Stoneham's rhetorical question "How can $p$ give us any reason to believe $q$ is true if the truth of $p$ does not make $q$ any more likely?" can now be answered: $p$ can be a reason to believe $q$ if it raises the degree of confirmation of $q$, even though it does not increase the probability of $q$.

As we have seen, Stoneham finds it "hard to see how there could be counter-examples" to (5). Let me therefore conclude by presenting a counterexample to (5b). ${ }^{6}$ Consider the three propositions

$$
\begin{aligned}
p & =\text { Bobby is a girl } \\
q & =\text { Billy is a girl } \\
S & =\text { Bobby and Billy are twins }
\end{aligned}
$$

then the antecedent of $(5 b)$ is true but its consequent is false.

The names 'Bobby' and 'Billy' can be used for boys as well as for girls. Since we do not know whether Bobby and Billy are in fact boys or girls, and since the statement that they are twins $(S)$ does not affect the probability of their being boys or girls, it is the case that:

\footnotetext{
5 The reason for translating the antecedent of (5), i.e. 'The belief that $p$ epistemically supports the belief that $q$ ', into the antecedent of (5a) and thus into a comparison of two epistemic supports, is that I wanted to stay close to Stoneham's notation - see note 3. I thank Tomoji Shogenji for making this point.

6 Thanks to David Atkinson for help with constructing this counterexample.
} 


$$
\begin{aligned}
\operatorname{pr}(p) & =\operatorname{pr}(q)=\operatorname{pr}(p \mid S)=\operatorname{pr}(q \mid S)=1 / 2 \\
\operatorname{pr}(\neg p) & =\operatorname{pr}(\neg q)=\operatorname{pr}(\neg p \mid S)=\operatorname{pr}(\neg q \mid S)=1 / 2,
\end{aligned}
$$

which precisely reflects Stoneham's assumption that $S$ is neutral with respect to $p$ or $q$. Further, since $p$ and $q$ are independent, it follows that

$$
\operatorname{pr}(p \& q)=1 / 2 \times 1 / 2=1 / 4
$$

However, $8 \%$ of all twins are monozygotic (so-called identical twins), and these are always of the same sex. Thus the information that Bobby and Billy are twins slightly increases the probability that they are of the same sex, and slightly decreases the probability that they are of different sexes. Hence the probability that Bobby and Billy are both girls, given that they are twins, is slightly more than a quarter:

$$
\operatorname{pr}(p \& q \mid S)=1 / 4+\varepsilon
$$

where we can in fact calculate $\varepsilon=0.02$. So the probability that Billy and Bobby are both girls is 0.27 (as is the probability that they are both boys). Note that $\operatorname{pr}(p \& q \mid S$ ) is quite a lot less than $\operatorname{pr}(p \mid S)$ or $\operatorname{pr}(q \mid S)$, so there is no question of a conjunction fallacy:

$$
\operatorname{pr}(p \& q \mid S)<\operatorname{pr}(q \mid S) \text { or } \operatorname{pr}(p \mid S) \text {. }
$$

Nevertheless, $\mathrm{D}(p \& q, S)$ is greater than $\mathrm{D}(p, S)$ or $\mathrm{D}(q, S)$. For

$$
\begin{aligned}
\mathrm{D}(p \& q, S) & =\operatorname{pr}(p \& q \mid S)-\operatorname{pr}(p \& q) \\
& =1 / 4+\varepsilon-1 / 4=\varepsilon
\end{aligned}
$$

whereas

$$
\begin{aligned}
& \mathrm{D}(p, S)=\operatorname{pr}(p \mid S)-\operatorname{pr}(p)=1 / 2-1 / 2=0 \\
& \mathrm{D}(q, S)=\operatorname{pr}(q \mid S)-\operatorname{pr}(q)=1 / 2-1 / 2=0 .
\end{aligned}
$$

So

$$
\mathrm{D}(p \& q, S)>\mathrm{D}(q, S) \text { or } \mathrm{D}(p, S)
$$

Thus we have an example in which the conjunction $p \& q$ has a smaller probability but a greater confirmation than either $p$ or $q$ has separately-everything conditioned by $S$. With the eminently reasonable identification of epistemic support as a measure of confirmation, I conclude that no violation of the probability calculus has occurred. What Stoneham sees as a probabilistic conjunction fallacy that is fatal to coherentism is in fact a perfectly legitimate conjunction effect for degrees of confirmation. 
Acknowledgements Thanks to the audience of the workshop 'Confirmation, Probability, and Fallacies' in Leuven for their remarks, to Tomoji Shogenji for his detailed comments afterwards, and to Tom Stoneham and Christoph Jäger for their reactions to earlier versions of this paper.

Open Access This article is distributed under the terms of the Creative Commons Attribution Noncommercial License which permits any noncommercial use, distribution, and reproduction in any medium, provided the original author(s) and source are credited.

\section{References}

Crupi, V., Tentori, K., \& Gonzalez, M. (2007). On Bayesian measures of evidential support: Theoretical and empirical issues. Philosophy of Science, 74, 229-252.

Crupi, V., Fitelson, B., \& Tentori, K. (2008). Probability, confirmation, and the conjunction fallacy. Thinking and Reasoning, 14.2, 182-199.

Fitelson, B. (1999). The plurality of Bayesian measures of confirmation and the problem of measure sensitivity. Philosophy of Science, 66, 363-378.

Jäger, Ch. (2007). Is coherentism coherent? Analysis, 67.4, 341-344.

Noordhof, P. (2007). A coherentist response to Stoneham's reductio. Analysis, 67.3, 257-258.

Rowbottom, D. P. (2007). A refutation of foundationalism? Analysis, 67.4, 345-346.

Shackel, N. (2008). Coherentism and the symmetry of epistemic support. Analysis, 68.3, 326-334.

Shogenji, T. (2003). A condition for transitivity in probabilistic support. British Journal for the Philosophy of Science, 54, 613-616.

Stoneham, T. (2007). A reductio of coherentism. Analysis, 67.3, 254-257. 